\title{
Two types of S phase precipitates in Al-Cu-Mg alloys
}

\author{
S.C. Wang ${ }^{a, b, *}$, M.J. Starink ${ }^{a}$ \\ ${ }^{a}$ Materials Research Group, School of Engineering Sciences, The University of Southampton, SO17 1BJ, U.K. \\ ${ }^{b}$ Electron Microscopy Centre, Faculty of Engineering and Science, The University of Southampton, SO17 1BJ, U.K. \\ * Corresponding author. E-mail address: wangs@soton.ac.uk (S.C. Wang)
}

Received 3 August 2006; received in revised form 1 September 2006; accepted 1 September 2006

Available online 28 November 2006

\begin{abstract}
Transmission electron microscopy (TEM) and differential scanning calorimetry (DSC) have been used to study S phase precipitation in an Al-4.2Cu-1.5Mg-0.6Mn-0.5Si (AA2024) and an Al-4.2Cu-1.5Mg-0.6Mn-0.08Si (AA2324) (wt.\%) alloy. In DSC experiments on as solution treated samples two distinct exothermic peaks are observed in the range $250-350^{\circ} \mathrm{C}$, whereas only one peak is observed in solution treated and subsequently stretched or cold worked samples. Samples heated to $270^{\circ} \mathrm{C}$ and $400^{\circ} \mathrm{C}$ at a rate of $10^{\circ} \mathrm{C} / \mathrm{min}$ in the DSC have been studied by TEM. The selected area diffraction patterns show that $\mathrm{S}$ phase precipitates with the classic orientation relationship form during the lower temperature peak, and for the solution treated samples, the higher temperature peak is caused by the formation of a second type of S phase precipitates which have an orientation relationship that is rotated by $\sim 4^{\circ}$ to the classic one. The effects of $\mathrm{Si}$ and cold work on the formation of second type of $\mathrm{S}$ precipitates have been discussed.
\end{abstract}

Keywords: Al-Cu-Mg alloy; S precipitate; TEM; DSC; orientation relationship

\section{Introduction}

The high strength AA2024 alloys (nominal compositions around Al-4.2Cu-1.5Mg-0.6Mn (wt.\%)) are a primary structural material used in the aircraft industry. The derivatives AA2x24 $(x=1-5)$, with stricter limits on Fe and Si impurity levels as well as other recent improved versions of AA2024, have improved toughness, fatigue resistance and strength. These alloys are specified for many aerospace structural applications, such as in fuselage structures, wing tension members, shear webs and ribs. The AA2x24 series alloys are strengthened by microstructure evolution during ageing.

In the early 1950s, Bagaryatsky [1] first proposed a 4-stage precipitation sequence for the ageing of Al-CuMg alloys:

$$
\mathrm{SSS} \rightarrow \mathrm{GPB} \text { zone } \rightarrow \mathrm{S}^{\prime \prime} / \mathrm{GPB} 2 \rightarrow \mathrm{S}^{\prime} \rightarrow \mathrm{S}
$$

where SSS stands for supersaturated solid solution and GPB stands for Guinier-Preston-Bagaryatsky (a term popularised by Silcock [2] and subsequent workers). Bagaryatsky [1] considered the GPB zone to be a short-range ordering of $\mathrm{Cu}$ and $\mathrm{Mg}$ solute atoms. The structure of S"/GPB2 has not been clearly confirmed. Orthorhombic [1,3-5], cubic [2], tetragonal [6,7] and monoclinic [8] structures have been proposed for the S"/GPB2 structure. S phase with composition of $\mathrm{Al}_{2} \mathrm{CuMg}$ has been determined as orthorhombic $\mathrm{Cmcm}$ structure with lattice parameters $a_{\mathrm{S}}=0.400 \mathrm{~nm}, b_{\mathrm{S}}=0.923 \mathrm{~nm}, c_{\mathrm{S}}=0.714 \mathrm{~nm}$ by Perlitz and Westgren [9] (PW) on the basis of X-ray diffraction (XRD) work. The S phase is an equilibrium phase and is incoherent with the Al matrix. Other models for the $\mathrm{S}$ phase have been reported [4], but the most accepted structure for S phase is PW model. The S' phase has generally been considered as semi-coherent with the matrix, possessing the same structure to $\mathrm{S}$ phase with slightly different lattice parameters of $a_{\mathrm{S}^{\prime}}=0.404 \mathrm{~nm}, b_{\mathrm{S}^{\prime}}=0.925 \mathrm{~nm}, c_{\mathrm{S}^{\prime}}=0.718 \mathrm{~nm}[1,10]$. As the proposed $\mathrm{S}^{\prime}$ structures have essentially the same crystal structures as $\mathrm{S}$ phase, with very small differences in lattice parameters, many recent publications make no distinction between the $\mathrm{S}^{\prime}$ and $\mathrm{S}$ phase. On the other hand, Charai et al. [8] suggested that the asymmetric shape of the differential scanning calorimetry (DSC) peaks in the range of $290-370^{\circ} \mathrm{C}$ in $\mathrm{Al}-2.1 \mathrm{Cu}-$ 
$1.3 \mathrm{Mg}-0.09 \mathrm{Zr}-0.04 \mathrm{Si}$ (wt.\%) indicated the presence of both $\mathrm{S}^{\prime}$ and $\mathrm{S}$ phases: orthorhombic semi-coherent $\mathrm{S}^{\prime}$ was reported to possess lattice parameters $a_{\mathrm{S}^{\prime}}=0.405 \mathrm{~nm}, b_{\mathrm{S}^{\prime}}=0.89 \mathrm{~nm}, c_{\mathrm{S}^{\prime}}=0.76 \mathrm{~nm}$ and the incoherent equilibrium $\mathrm{S}$ phase was reported with $a_{\mathrm{S}}=0.405 \mathrm{~nm}, b_{\mathrm{S}}=0.921 \pm 0.006 \mathrm{~nm}, c_{\mathrm{S}}=0.719 \pm 0.012 \mathrm{~nm}$.

The $S$ and $S^{\prime}$ phases have been reported to precipitate in the form of laths with the $\{120\}_{\mathrm{Al}}$ habit planes elongated along $\langle 100\rangle_{\mathrm{Al}}$ direction [1,11]. Both phases have been suggested to possess the same orientation relationship (OR) with aluminium matrix as follows $[1,8]$ :

$$
[100]_{\mathrm{S}\left(\mathrm{S}^{\prime}\right)} / /[100]_{\mathrm{Al}},[010]_{\mathrm{S}\left(\mathrm{S}^{\prime}\right)} / /[02 \overline{1}]_{\mathrm{Al}},[001]_{\mathrm{S}\left(\mathrm{S}^{\prime}\right)} / /[012]_{\mathrm{Al}}
$$

where the subscript Al stands for aluminium matrix. The OR between the distorted S" phase and the matrix was proposed as follows $[1,12]$ :

$$
[100]_{\mathrm{S}^{\prime \prime}} / /[100]_{\mathrm{Al}},[0 \overline{1} 1]_{\mathrm{S}^{\prime \prime}} / /[0 \overline{5} 3]_{\mathrm{Al}},[013]_{\mathrm{S}^{\prime \prime}} / /[011]_{\mathrm{Al}}
$$

Based on the matrix transformation by Li and Yan [13], the (OR2) is equivalent to:

$$
[100]_{\mathrm{S}^{\prime \prime}} / /[100]_{\mathrm{Al}},[010]_{\mathrm{S}^{\prime \prime}} / /[05 \overline{2}]_{\mathrm{Al}},[001]_{\mathrm{S}^{\prime \prime}} / /[025]_{\mathrm{Al}}
$$

Since the mid 1990s, atom probe field ion microscopy (APFIM) and three-dimensional atom-probe (3DAP) have evidenced that the first stage of age hardening is due to the formation of co-clusters [14-17]. Ringer et al. $[14,15]$ proposed the following 3-stage precipitation sequences for the ageing of $\mathrm{Al}-\mathrm{Cu}-\mathrm{Mg}$ alloys:

$$
\mathrm{SSS} \rightarrow \mathrm{Cu}-\mathrm{Mg} \text { co-clusters } \rightarrow \mathrm{GPB} \text { zone } \rightarrow \mathrm{S}
$$

where the $\mathrm{Cu}-\mathrm{Mg}$ co-clusters are responsible for the initial hardening, GPB zone is the dominant precipitate at peak strengthening and the $\mathrm{S}$ phase appears in the softening stage.

By combination of transmission electron microscopy (TEM) and DSC, Wang et al $[18,19]$ confirmed the existence of S" [4] and confirmed that the peak strengthening in quenched and subsequently stretched $\mathrm{Al}-\mathrm{Cu}-\mathrm{Mg}$ alloys corresponds to $\mathrm{S}$ phase. Thus the following 3-stage precipitation sequence was proposed:

$$
\mathrm{SSS} \rightarrow \mathrm{Cu}-\mathrm{Mg} \text { co-clusters } \rightarrow \mathrm{S} / \mathrm{GPB} 2 \rightarrow \mathrm{S}
$$

where the $\mathrm{S}$ phase is responsible for the peak strengthening. S"/GPB2 was considered to provide only limited contribution to strengthening for alloys with substantial $\mathrm{Cu}$ content [20].

The S precipitates commonly observed are lath shaped having habit planes of $\{210\}_{\mathrm{Al}} / /(010)_{\mathrm{S}}$ and lath axis of $\{100\}_{\mathrm{Al}} / /(100)_{\mathrm{S}}$, whose orientation relationship with Al matrix satisfies (OR1). But, using HREM, Zhang et al. [21] first observed some $\mathrm{S}^{\prime}(\mathrm{S})$ precipitates with the habit plane between the $(021)_{\mathrm{S}^{\prime}}$ and $(043)_{\mathrm{S}^{\prime}}$ in $\mathrm{Al}-4.43 \mathrm{Cu}-$ $2.00 \mathrm{Mg}-0.53 \mathrm{Mn}$ (wt.\%) after water quenching and aged at $250^{\circ} \mathrm{C}$ for $6 \mathrm{~h}$. Radmilovic et al. [22] observed a similar type of precipitates, in the $\mathrm{Al}-2.01 \mathrm{Cu}-1.06 \mathrm{Mg}-0.14 \mathrm{Zr}-0.08 \mathrm{Fe}$ (wt.\%) after quenching into ice brine and ageing for $72 \mathrm{~h}$ at $190^{\circ} \mathrm{C}$, which had habit planes of $\{210\}_{\mathrm{Al}} / /(043)_{\mathrm{S}}$ and were designated as Type II precipitates. The precipitates which followed (OR1) were designated as Type I. Both types of S phase precipitates had the same lattice parameters of $a_{\mathrm{S}}=0.403 \pm 0.001 \mathrm{~nm}, b_{\mathrm{S}}=0.930 \pm 0.013 \mathrm{~nm}, c_{\mathrm{S}}=0.708 \pm 0.01 \mathrm{~nm}$ [22]. However, the relationship between the two types of S precipitates has not been given. Majimel et al. [23], studying an Al-2.66Cu$1.85 \mathrm{Mg}-0.2 \mathrm{Fe}-0.21 \mathrm{Si}-0.34 \mathrm{Mn}-0.23 \mathrm{Ni}-0.09 \mathrm{Ti}$ (wt.\%) (AA2650) alloy, observed that the differences between the two orientation variants ranged over several degrees, with most of the data falling into a range of about 4-6 $6^{\circ}$ The following orientation relationship was satisfied:

$$
[100]_{\mathrm{S}} / /[100]_{\mathrm{Al}},[010]_{\mathrm{S}} / /[05 \overline{2}]_{\mathrm{Al}},[001]_{\mathrm{S}} / /[025]_{\mathrm{Al}}
$$

In recent work on a quenched and aged Al-2.96Mg-0.42Cu-0.12Si-0.25Mn-0.21Fe (wt.\%), alloy, Kovarik et al. [24] also reported the existence of Type II precipitates. As (OR3) has the same orientation relationship as (OR2a), they referred to Type II S phase as S" phase, which is the distorted S structure proposed by Bagaryatsky [1]. Energy dispersive X-ray spectrometry (EDS) and atom probe tomography analysis indicated that the Type II S phase was slightly enriched in $\mathrm{Si}$ [24]. The driving force for the formation of Type II was explained to result from an invariant line transformation strain [22], or related to a competition between the length of the $(001)_{S}$ and $(021)_{S}$ interfaces [24].

Throughout the various works cited above the sequence in which these S phase variants appeared is unclear and little is know about the factors determining the predominance of either of the variants. Clarification of this is essential to understand the strengthening in Al-Cu-Mg alloys, and is the purpose of this study. To identify the effect of $\mathrm{Si}$ on the formation of Type II precipitates, we compared the commercial AA2024 alloy and its high purity variant AA2324 alloy by DSC and TEM. 


\section{Experimental procedures}

The chemical compositions of the AA2024 and AA2324 alloys studied are given in the Table 1. The Si and Fe contents are close to the maximum allowable for the two alloys. The alloys were supplied in the form of $13 \mathrm{~mm}$ plate in T351 (solution treated, quenched, stretched 1.5-3\%) condition.

Table 1 Chemical compositions of AA2024 and AA2324 alloys (wt.\%)

\begin{tabular}{ccccccc}
\hline Alloy & $\mathrm{Cu}$ & $\mathrm{Mg}$ & $\mathrm{Mn}$ & $\mathrm{Si}$ & $\mathrm{Fe}$ & $\mathrm{Al}$ \\
\hline AA2024 & 4.19 & 1.5 & 0.62 & 0.49 & 0.48 & $\mathrm{Bal}$ \\
AA2324 & 4.19 & 1.5 & 0.62 & 0.08 & 0.06 & $\mathrm{Bal}$ \\
\hline
\end{tabular}

Table 2 shows the heat treatments and working performed on the samples. For all treatments slices of initially about $3 \mathrm{~mm}$ thickness and diameter about $5 \mathrm{~mm}$ were used. All solution treatments were performed at $495^{\circ} \mathrm{C}$. Cold working was achieved by uniaxially compressing the samples (essentially a miniature cold forging) to reduce the thickness by $10 \%$. DSC runs were performed using a Perkin Elmer Pyris 1 apparatus at a constant heating rate of $10^{\circ} \mathrm{C} / \mathrm{min}$. The reference sample was an empty pure aluminium pan, tests were carried out using a nitrogen gas flow. Baseline correction procedures are outlined elsewhere [25], all presented DSC curves reflect the heat flow due to reactions. Due to the strong differences in the DSC curves from the different samples, slight inaccuracies in baseline determination in the order of $\pm 5 \times 10^{-3} \mathrm{~W} / \mathrm{g}$ may remain. DSC experiments on all samples except the as received T351 sample were started within $1 \mathrm{~min}$ of the final treatment.

The second series of DSC runs were carried out to produce samples for TEM observations as shown in Table 3. The samples were heated in the DSC and the heating was stopped at two selected temperatures of $270^{\circ} \mathrm{C}$ and $400^{\circ} \mathrm{C}$ and subsequently cooled down in the DSC furnace (cooling speed is estimated at about of $200^{\circ} \mathrm{C} / \mathrm{min}$ ). Disks of $3 \mathrm{~mm}$ in diameter were punched out from these slices, ground to about $0.20 \mathrm{~mm}$ in thickness and then electropolished using a solution of $\mathrm{HNO}_{3}$ and methanol (1:3 in volume). TEM foils were examined using a JEOL 3010 microscope operating at $300 \mathrm{kV}$, and analysed with EDS. For all conditions the ORs of at least 3 precipitates were analysed by means of SAD, and as all analysed precipitates within each sample were found to have the same OR, data on one typical precipitate is presented.

Table 2 Heat treatments for DSC samples

\begin{tabular}{|c|c|}
\hline $\begin{array}{l}\text { Designated names for } \\
\text { the heat treatments }\end{array}$ & Details \\
\hline T351 & Solution treated at $495^{\circ} \mathrm{C}$, quenched, stretched $1.5-3 \%$, and aged at room temperature for several months \\
\hline WQ & $\mathrm{T} 351+$ solution treated at $495^{\circ} \mathrm{C}$ for $30 \mathrm{~min}+$ water quenched. \\
\hline WQ+cold worked & $\mathrm{T} 351+$ solution treated at $495^{\circ} \mathrm{C}$ for $30 \mathrm{~min}+$ water quenched + immediately cold worked by $10 \%$. \\
\hline
\end{tabular}

Table 3 Heat treatments for TEM samples

\begin{tabular}{|c|c|}
\hline $\begin{array}{l}\text { Designated names for the } \\
\text { heat treatments }\end{array}$ & Details \\
\hline WQ-270 & $\mathrm{T} 351+$ solution treated at $495^{\circ} \mathrm{C}$ for $30 \mathrm{~min}+$ water quenched + heated at $10^{\circ} \mathrm{C} / \mathrm{min}$ to $270^{\circ} \mathrm{C}$. \\
\hline WQ-400 & $\mathrm{T} 351+$ solution treated at $495^{\circ} \mathrm{C}$ for $30 \mathrm{~min}+$ water quenched + heated at $10^{\circ} \mathrm{C} / \mathrm{min}$ to $400^{\circ} \mathrm{C}$. \\
\hline WQ-cold worked-270 & $\begin{array}{c}\mathrm{T} 351+\text { solution treated at } 495^{\circ} \mathrm{C} \text { for } 30 \mathrm{~min}+\text { water quenched }+ \text { immediately } 10 \% \text { cold } \\
\text { worked }+ \text { heated at } 10^{\circ} \mathrm{C} / \mathrm{min} \text { to } 270^{\circ} \mathrm{C} \text {. }\end{array}$ \\
\hline WQ-cold worked-400 & $\begin{array}{l}\mathrm{T} 351+\text { solution treated at } 495^{\circ} \mathrm{C} \text { for } 30 \mathrm{~min}+\text { water quenched }+ \text { immediately } 10 \% \text { cold } \\
\text { worked }+ \text { heated at } 10^{\circ} \mathrm{C} / \mathrm{min} \text { to } 400^{\circ} \mathrm{C} \text {. }\end{array}$ \\
\hline WQ-cold worked-400-1h & $\begin{array}{l}\mathrm{T} 351+\text { solution treated at } 495^{\circ} \mathrm{C} \text { for } 30 \mathrm{~min}+\text { water quenched }+ \text { immediately } 10 \% \text { cold } \\
\text { worked }+ \text { heated at } 10^{\circ} \mathrm{C} / \mathrm{min} \text { to } 400^{\circ} \mathrm{C} \text { and held for } 1 \mathrm{~h} \text { at } 400^{\circ} \mathrm{C} \text {. }\end{array}$ \\
\hline
\end{tabular}




\section{Results}

Fig. 1 shows the DSC curves of the AA2324 alloy in three different conditions. Five main effects may be identified in these thermograms [25-27]: an exothermic peak, $\mathrm{A}$, between $60^{\circ} \mathrm{C}$ and $110^{\circ} \mathrm{C}$, is due to the formation of co-clusters [17,20]; an endothermic effect, $\mathrm{B}$, between $160^{\circ} \mathrm{C}$ and $240^{\circ} \mathrm{C}$ may be attributed to $\mathrm{Cu}-\mathrm{Mg}$ co-cluster dissolution (with possibly some GPB2 dissolution); an exothermic effect $\mathrm{C}$ (containing two overlapping reactions, see below) between about $230^{\circ} \mathrm{C}$ and $340^{\circ} \mathrm{C}$, is attributed to the formation of $\mathrm{S}$ phase precipitates; a broad endothermic effect, $\mathrm{D}, 340^{\circ} \mathrm{C}-500^{\circ} \mathrm{C}$, is identified as progressive dissolution of the $\mathrm{S}$ precipitates [25,28]; an endothermic sharp peak, $\mathrm{E}$, between $505^{\circ} \mathrm{C}$ and $515^{\circ} \mathrm{C}$ is believed to be due to the (partial) melting of $\mathrm{S}+\theta$ eutectics. In this study, exothermic effect $\mathrm{C}$ is analysed. For the deformed samples, T351 (1.5-3\% stretch) and WQ+cold worked, exothermic effect $\mathrm{C}$ shows only one single peak. This peak shifts to lower temperature with increasing deformation, which is considered to be due to an increase in heterogeneous nucleation sites for $\mathrm{S}$ phase (predominantly dislocations) [29]. In contrast, the sample in WQ condition shows two distinct peaks. To confirm which kind of precipitates are responsible for these two exothermic effects, the samples were heated in DSC at a heating rate of $10^{\circ} \mathrm{C} / \mathrm{min}$ up to 270 and $400^{\circ} \mathrm{C}$ respectively. Then the samples were prepared and observed in TEM.

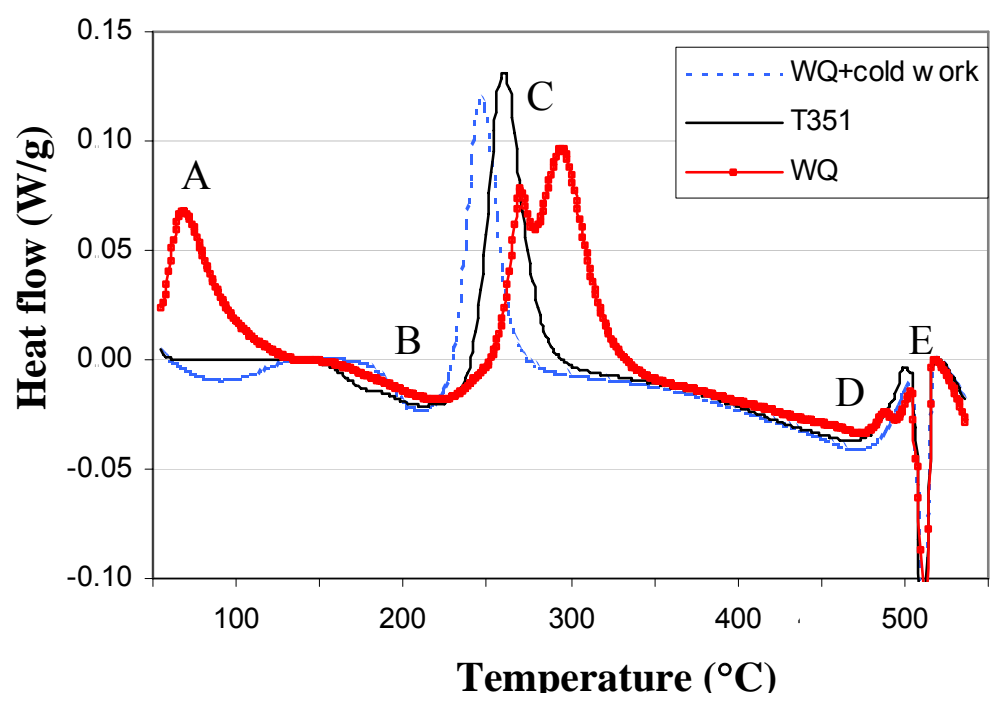

Fig.1 DSC thermogram of the AA2324 alloy in T351, WQ and WQ+cold worked conditions.

Fig. 2(a) shows an S precipitate with flat interface for the solution treated AA2324 alloy heated to $270^{\circ} \mathrm{C}$ in the DSC. The lath shape S phase precipitate has a cross section of about $150 \times 250 \mathrm{~nm}$. Fig. 2(b) shows [001] $]_{\mathrm{Al}}$ and $[100]_{\mathrm{S}}$ selected area diffraction (SAD) patterns. The orientation relationship between the $\mathrm{S}$ precipitate and matrix satisfies (OR1). The S phase lattice parameters were measured to be $a_{\mathrm{S}}=0.400 \pm 0.005 \mathrm{~nm}, b_{\mathrm{S}}=0.921 \pm 0.005 \mathrm{~nm}, c_{\mathrm{S}}$ $=0.718 \pm 0.005 \mathrm{~nm}$. The flat interface is the $(001)_{\mathrm{S}}$ plane, which is consistent to Type I S phase precipitates. Fig. 2 (c) is the corresponding simulation based on (OR1) and the above lattice parameters, which matches the pattern shown in Fig. 2(b) well.

Fig. 3(a) shows a lens shaped S phase precipitate in the AA2324 alloy heated to $400^{\circ} \mathrm{C}$ in the DSC. The S phase precipitates measures about $150 \times 300 \mathrm{~nm}$. Fig. 3(b) shows $[001]_{\mathrm{Al}}$ and [100] $\mathrm{S}$ SAD patterns. The orientation relationship between the $\mathrm{S}$ phase precipitate and matrix was found to deviate $\sim 4^{\circ}$ from (OR1). The modified $\mathrm{S}$ phase precipitate is therefore referred to as a Type II S phase precipitate and lattice parameters were measured to be $a_{\mathrm{S}}=0.400 \pm 0.005 \mathrm{~nm}, b_{\mathrm{S}}=0.917 \pm 0.005 \mathrm{~nm}, c_{\mathrm{S}}=0.714 \pm 0.005 \mathrm{~nm}$, which is consistent with Type I precipitate in Fig. 2. Fig. 3(c) shows the simulated pattern which matches the pattern shown in Fig. 3(b). EDS has been used to analyse the composition at three key positions: in the S phase, at edge of S phase and in the matrix nearby. Three randomly chosen precipitates have been analysed and the average compositions are shown in Table 4 and illustrated in Fig. 3(d). 


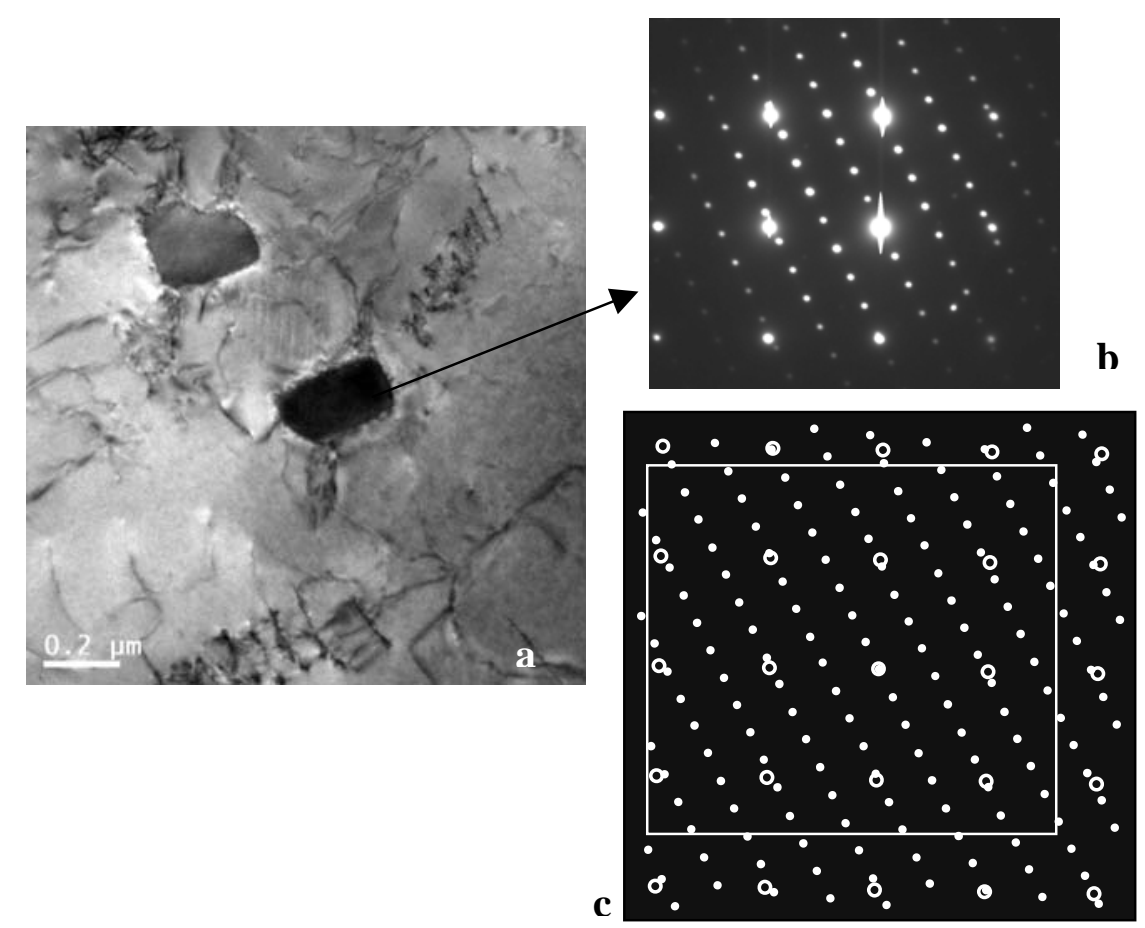

Fig. 2 TEM micrographs and corresponding diffraction patterns of the AA2324 alloy in WQ-270 condition. (a) bright field; (b) $[001]_{\mathrm{Al}} \mathrm{SAD}$ pattern of the $\mathrm{S}$ phase precipitate in dark contrast in Fig. 2(a) with surrounding matrix (the streaks emanating from the brighter Al spots are an artefact due to camera saturation); (c) simulated SAD pattern corresponding to (OR1). The rectangle corresponds to the range of Fig. 2(b).
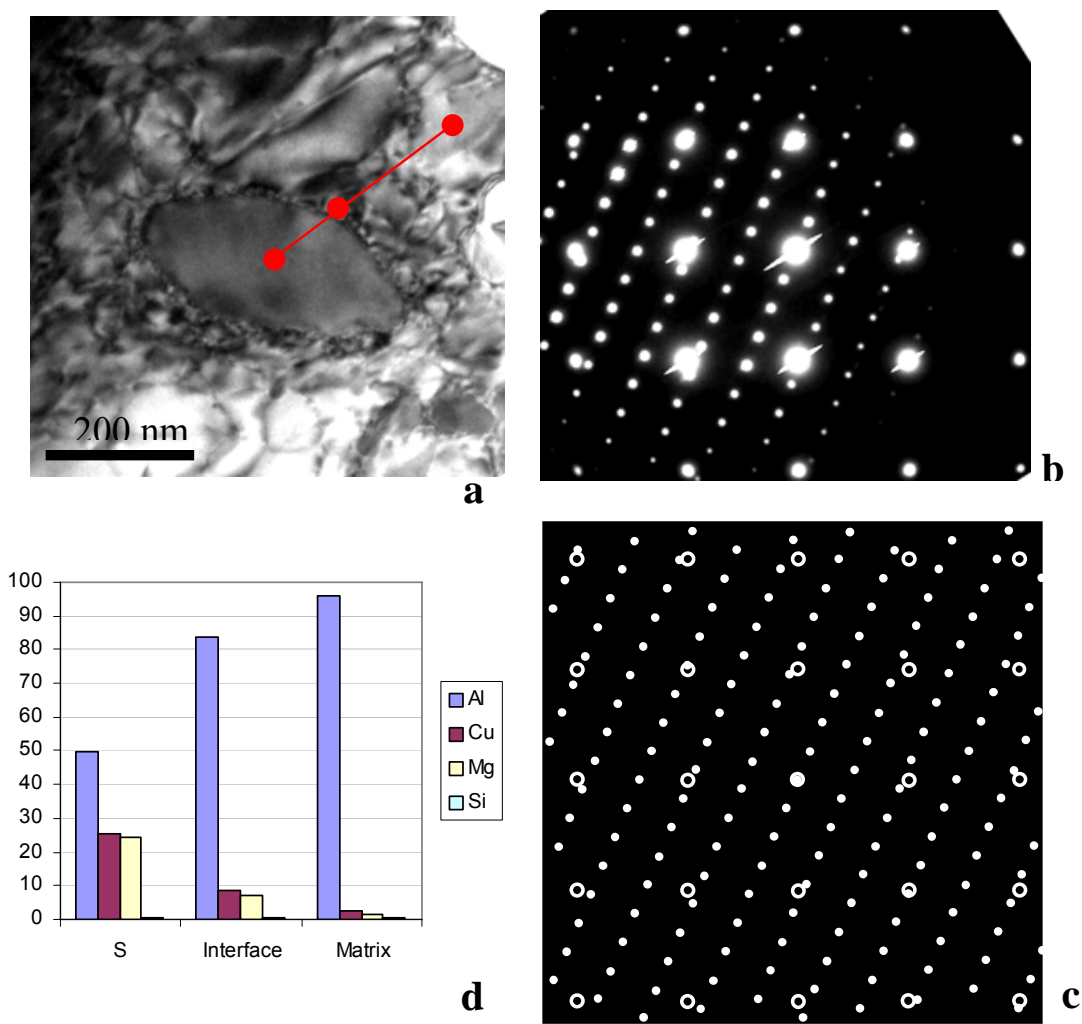

Fig. 3 TEM micrographs and corresponding diffraction patterns of AA2324 alloy at WQ-400 condition. (a)bright field; (b) $[001]_{\mathrm{Al}} \mathrm{SAD}$ pattern of the $\mathrm{S}$ phase precipitate in dark contrast in Fig. 3(a) with surrounding Al matrix; (c) simulated SAD pattern after rotating $4^{\circ}$ from (OR1). (d) composition from EDS at three key points (the streaks emanating from the brighter $\mathrm{Al}$ spots are an artefact due to camera saturation). 
Table 4. The compositions of three regions in and around one modified $\mathrm{S}$ phase precipitate (at.\%)

\begin{tabular}{ccccc}
\hline Location & $\mathrm{Al}$ & $\mathrm{Cu}$ & $\mathrm{Mg}$ & $\mathrm{Si}$ \\
$\mathrm{S}$ & $50^{ \pm 1}$ & $25.5^{ \pm 0.5}$ & $24.5^{ \pm 0.5}$ & $0.15^{ \pm 0.1}$ \\
Interface & $83.8^{ \pm 0.6}$ & $8.9^{ \pm 0.3}$ & $7.2^{ \pm 0.3}$ & $0.17^{ \pm 0.1}$ \\
Matrix & $95.8^{ \pm 0.4}$ & $2.8^{ \pm 0.2}$ & $1.4^{ \pm 0.2}$ & $0.1^{ \pm 0.1}$ \\
\hline
\end{tabular}

The interfaces of Fig. 3(a) have been determined to be $(023)_{\mathrm{S}},(0 \overline{2} 3)_{\mathrm{S}},(010)_{\mathrm{S}},(0 \overline{1} 5)_{\mathrm{S}}$ as shown in Fig. 4a. Fig. 4(b) shows several Type II S precipitates in a low magnification. It seems that these precipitates have irregular shapes and interfaces, i.e. the interfaces for Type II S phase precipitates are not confined on one or two specific planes.
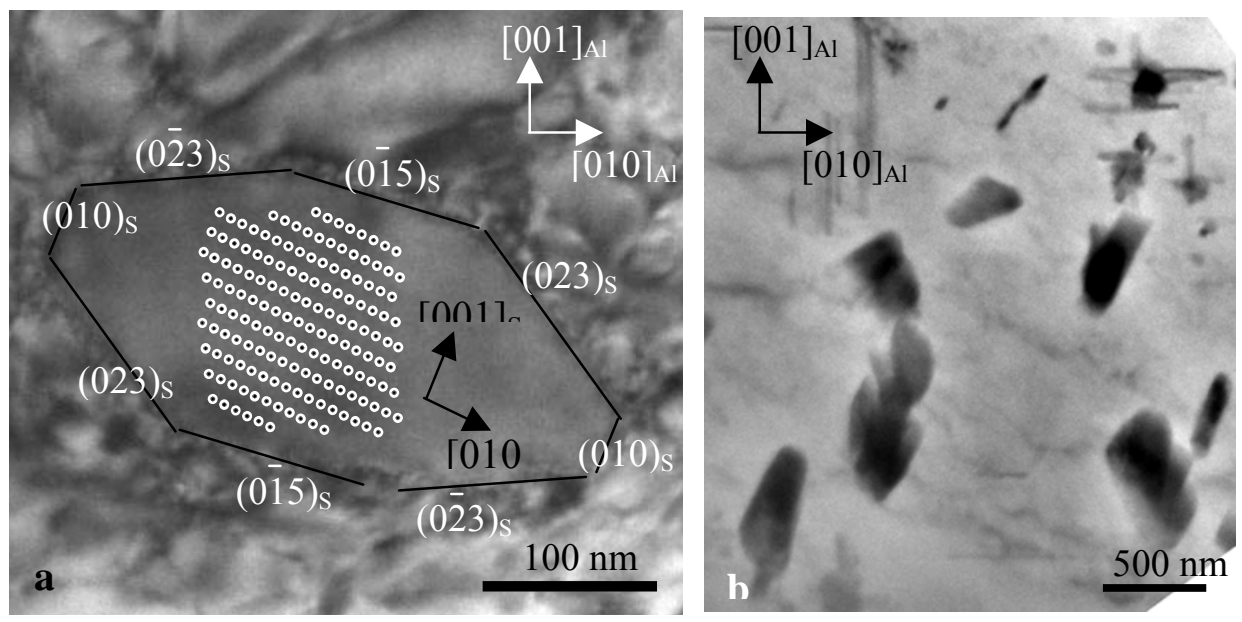

Fig. 4 TEM micrographs of AA2324 alloy at condition of WQ-400. (a) interface analysis for Fig. 3(a). The group of white dots in the middle of the particle is the enlargement of the HREM simulation for S phase; (b) Low magnification micrograph showing the irregular shapes of S phase.

To identify the effect of Si on the formation of Type II precipitates, a DSC run on a solution treated sample of the lower purity alloy AA2024 was performed. Results in Fig. 5 reveal that two exothermic peaks appear in both curves: The first peak $\mathrm{C}_{\mathrm{I}}$ is due to the formation of Type I precipitates, and the second peak $\mathrm{C}_{\mathrm{II}}$ is due to the formation of Type II precipitates. The peak temperatures for the formation of Type II precipitates (peak $\mathrm{C}_{\mathrm{II}}$ ) does not vary significantly between the AA2024 and the AA2324 sample: $\sim 296^{\circ} \mathrm{C}$ for AA2024 alloy with 0.49 wt $\% \mathrm{Si}$ and $\sim 300^{\circ} \mathrm{C}$ for AA2324 alloy with $0.08 \mathrm{wt} \% \mathrm{Si}$. However, the increased Si content enhances the amount of Type I $\mathrm{S}$ phase forming and reduces the amount of Type II S phase forming.

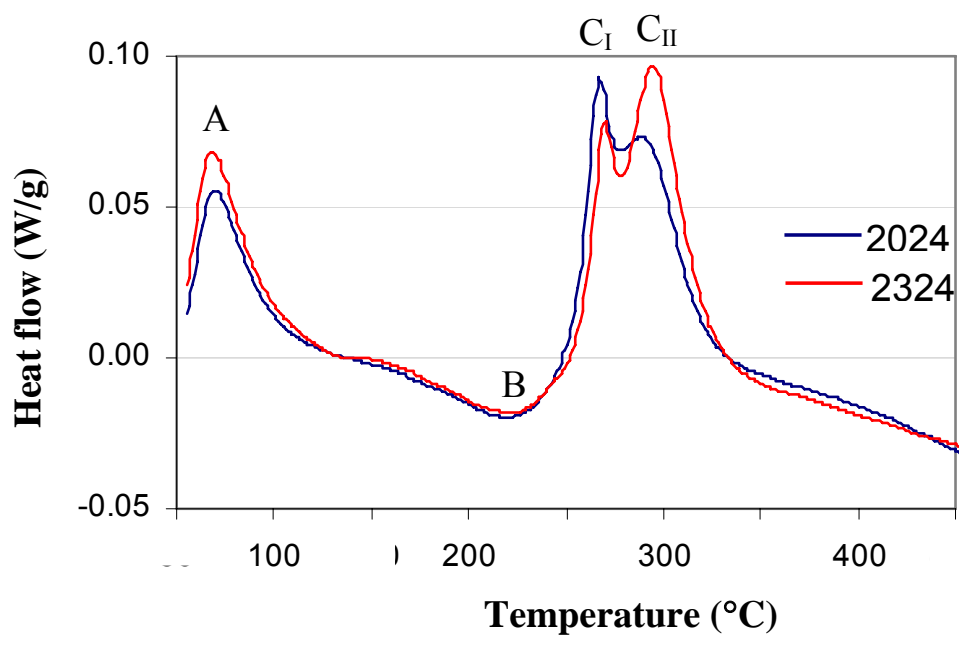

Fig.5 DSC thermograms of AA2024 and AA2324 alloys in WQ conditions. 
To study the effect of deformation on the formation of Type II precipitates, interrupted DSC was performed on the AA2324 alloy after water quenching and subsequent 10\% cold work. TEM analysis of WQ-cold worked-270 sample reveals lath shape $S$ phase with an average cross section approximately $25 \times 75 \mathrm{~nm}$ as shown in Fig. 6 (a), which is much smaller than in the non-deformed condition as shown in Fig. 2(a). Fig. 6(b) shows the [001] $]_{\mathrm{Al}} \mathrm{SAD}$ pattern and diffractions from a large number of precipitates. The orientation relationship between the $\mathrm{S}$ phase precipitates and the matrix is (OR1). The same OR is observed for samples in the WQ-cold worked-400 condition. The latter sample was further held for $1 \mathrm{~h}$ at $400^{\circ} \mathrm{C}$ to investigate whether there is any change in orientation relationship. Fig. 7(a) shows typical lath S precipitates for the condition of WQ-cold worked-400-1h. The lath shape $S$ phase has an average cross section of about $50 \times 100 \mathrm{~nm}$. Fig. 7(b) shows $[001]_{\mathrm{Al}}$ and $[100]_{\mathrm{S}} \mathrm{SAD}$ patterns. The orientation relationship between $\mathrm{S}$ and matrix was determined to be very close to (OR1), with only $1^{\circ}$ rotation with respect to the perfect (OR1).
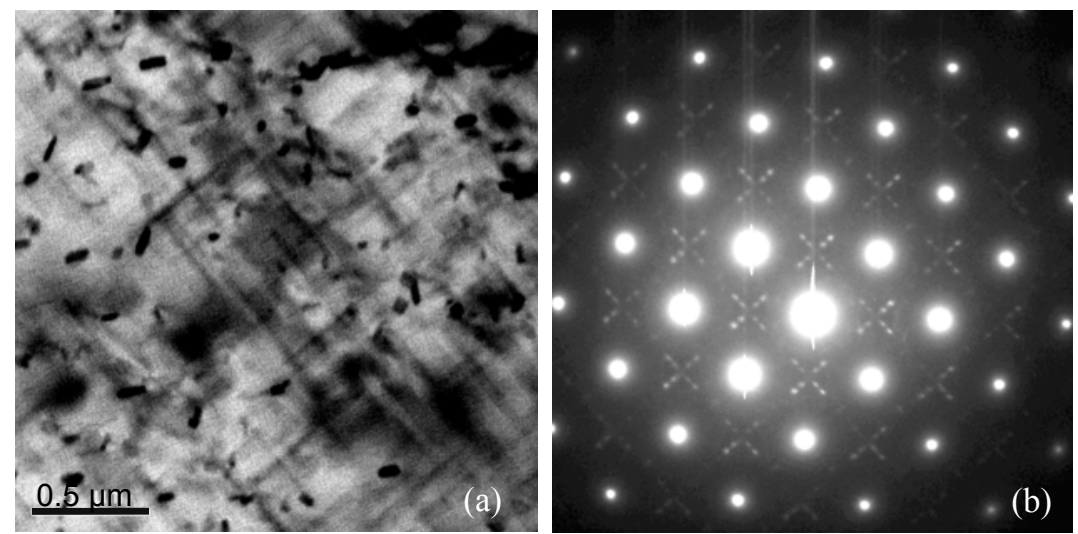

Fig. 6 TEM micrographs and corresponding diffraction patterns of AA2324 alloy in WQ-cold work-270 condition. (a) bright field showing lath $\mathrm{S}$ precipitates along $[100]_{\mathrm{Al}}$ and $[010]_{\mathrm{Al}}$ directions in weak contrast and cross sections of lath $\mathrm{S}$ precipitates along $[001]_{\mathrm{Al}}$ in dark contrast; (b) $[001]_{\mathrm{Al}}$ and $\left.\left.\langle 100\rangle_{\mathrm{S}},<021\right\rangle_{\mathrm{S}},<013\right\rangle_{\mathrm{S}}$ combined SAD patterns (the vertical streaks emanating from the brighter Al spots are an artefact due to camera saturation)
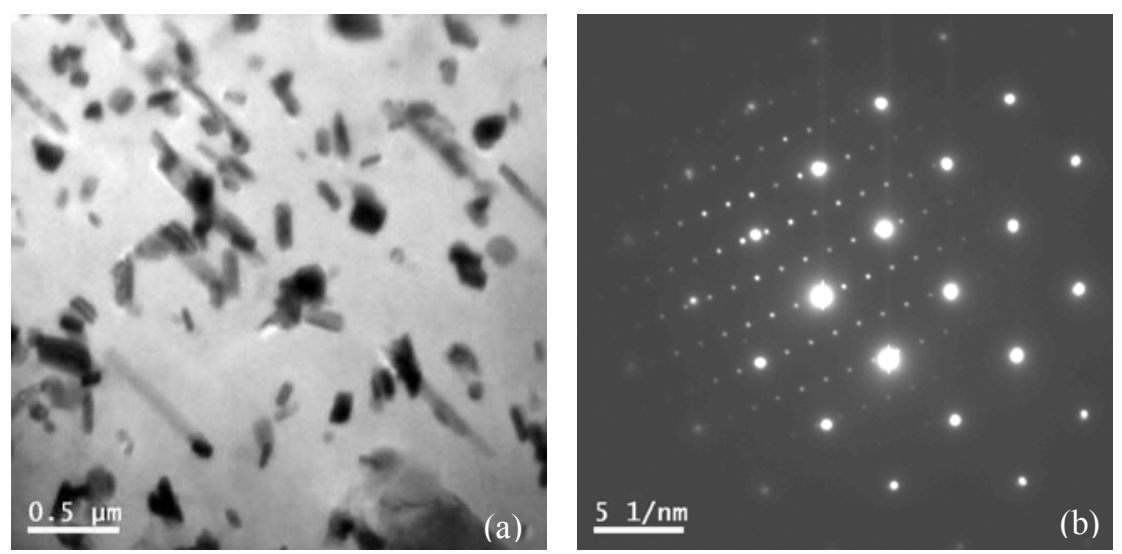

Fig. 7 TEM micrographs and corresponding diffraction patterns of AA2324 alloy in WQ-cold work-400-1h condition. (a) bright field; (b) $[001]_{\mathrm{Al}}$ and $[100]_{\mathrm{S}}$ combined SAD patterns.

\section{Discussion}

\subsection{Formation temperatures for Type I and II S phase}

TEM analysis of interrupted DSC experiments on the AA2324 alloy show that the peaks at 274 and $300^{\circ} \mathrm{C}$ (Fig. 1) are caused by the formation of two distinct types of $S$ phase precipitates, Types I and II S phase, respectively, with a $\sim 4^{\circ}$ difference in orientation relationship (Figs. $2 \& 3$ ). Zhang et al. [21] first reported the $\mathrm{S}$ 
precipitates with OR different from the common (OR1) in a sample of an Al-4.43Cu-2.00Mg-0.53Mn (wt.\%) alloy that was water quenched and aged at $250^{\circ} \mathrm{C}$ for $6 \mathrm{~h}$. Radmilovic et al. [22] observed Type II precipitates in a sample of an $\mathrm{Al}-2.01 \mathrm{Cu}-1.06 \mathrm{Mg}-0.14 \mathrm{Zr}-0.08 \mathrm{Fe}$ (wt.\%) alloy that was ice brine quenched and aged $72 \mathrm{~h}$ at $190^{\circ} \mathrm{C}$. Majimel et al. [23] observed Type II S phase in an Al-2.66Cu-1.85Mg-0.2Fe-0.21 Si-0.34Mn-0.23Ni (wt.\%) alloy that was solution treated, stretched, aged and exposed for $5000 \mathrm{~h}$ at $150^{\circ} \mathrm{C}$. On the other hand, studying an aged AA5xxx series alloy Al-2.96Mg-0.42Cu-0.12Si-0.25Mn-0.21Fe (wt.\%), which shows S phase formation, Kovarik et al. [24], also observed precipitates with a similar modified OR but referred to it as S" of Bagaryatsky structure. The first three studies [21-23] suggested that Type II precipitates coexisted with Type I, whereas Kovarik et al [24] proposed that Type II (S" phase) formed before Type I by rotation and changes into the classic OR.

To compare the isothermal ageing treatments for formation of Type II precipitates in the previous experiments with the non-isothermal treatments by DSC in this study, we will calculate the temperature compensated time for a single thermally activated reaction, which is defined as [25]:

$$
\int \exp \left(-\frac{E_{a}}{R T}\right) d t=\exp \left(-\frac{E_{a}}{R T_{e q}}\right) t_{e q}
$$

where $E_{a}$ is the activation energy for the reaction, $R$ is the gas constant $(8.314 \mathrm{~J} / \mathrm{K} \mathrm{mol}), T$ is a temperature reached during a non-isothermal treatment, $T_{e q}$ and $t_{e q}$ are an equivalent temperature and time in an isothermal heat treatment, respectively. The above expression for equivalent time can be used in many problems where the progress of a reaction during linear heating needs to be compared with the progress during isothermal aging (or linear heating at a different heating rate), and the integral can be approximated in several ways $[25,30]$. Table 5 shows the calculated DSC temperatures for the $\mathrm{S}$ phase reaction at heating rate of $10^{\circ} \mathrm{C} / \mathrm{min}$, which are equivalent to the isothermal treatments reported in Ref. [20-23] ( $E_{a}$ is $148 \mathrm{~kJ} / \mathrm{mol}$ for S phase formation [31]). The results indicate that all previous observations of Type II S phase in Refs [21-24] occurred at an ageing treatment equivalent to heating at $10{ }^{\circ} \mathrm{C} / \mathrm{min}$ to a temperature between 295 and $344^{\circ} \mathrm{C}$. This is consistent with the current observation that at heating rate of $10^{\circ} \mathrm{C} / \mathrm{min}$ the exothermic formation effect of Type II S phase in DSC is between 280 and 350, with a peak at $300^{\circ} \mathrm{C}$ (as shown in Fig. 1).

Table 5 Isothermal heat treatments producing Type II S phase variants for various solution treated $\mathrm{Al}-\mathrm{Cu}-\mathrm{Mg}$ alloys with equivalent temperature for DSC heating at $10^{\circ} \mathrm{C} / \mathrm{min}$ calculated using Eq. (1).

\begin{tabular}{lcccc}
\hline Ref. & {$[21]$} & {$[22]$} & {$[23]$} & {$[24]$} \\
\hline $\begin{array}{l}\text { Isothermal treatment } \\
\begin{array}{l}\text { Equivalent temperature } \\
\text { heated at } 10^{\circ} \mathrm{C} / \mathrm{min}\end{array}\end{array}$ & $250^{\circ} \mathrm{C} / 6 \mathrm{~h}$ & $190^{\circ} \mathrm{C} / 72 \mathrm{~h}$ & $150^{\circ} \mathrm{C} / 5000 \mathrm{~h}$ & $200^{\circ} \mathrm{C} / 16 \mathrm{~h}$ \\
\hline
\end{tabular}

\subsection{Formation of Type II precipitates}

Type I has a lath shape with the long flat surfaces of $(010)_{\mathrm{S}}$ and $(001)_{\mathrm{S}}$, whereas the observed habit plane in Type II precipitates is not flat. This can be understood from the fact that the invariant line interface is irrational and does not correspond to a low-index plane in either the matrix or the precipitate crystal [22]. The variation in orientation relationship and morphology was explained as result of an invariant line transformation strain [22], or related to a competition between the length of the $(001)_{S}$ and $(021)_{S}$ interfaces [24].

The interfaces of one Type II precipitate in this study have been determined to be $(023)_{\mathrm{S}},(0 \overline{2} 3)_{\mathrm{S}},(010)_{\mathrm{S}}$, $(0 \overline{1} 5)_{\mathrm{S}}$ as shown in Fig. 4(a) and several more interfaces for other precipitates are shown in Fig. 4(b). This is quite different from the interfaces reported in previous works: $(021)_{\mathrm{S}}$ and $(001)_{\mathrm{S}}$ for Type II S phase in a Al-2.01Cu$1.06 \mathrm{Mg}-0.14 \mathrm{Zr}-0.08 \mathrm{Fe}(\mathrm{wt} . \%)$ alloy [22], and $(021)_{\mathrm{S}},(001)_{\mathrm{S}},(043)_{\mathrm{S}}$ and $(031)_{\mathrm{S}}$ for a precipitate similar to Type II S phase in a Al-2.96Mg-0.42 Cu-0.12Si-0.25Mn-0.21Fe (wt.\%) alloy [24]. Our results indicate that the interfaces for Type II S phase precipitates are not confined to one or two specific planes. The wide range of interface planes observed in this study shows that previous suggestions that the formation of Type II are due to the invariant line interface [22] or one specific interface [24] can, in fact, not fully explain the observations, as both of these earlier suggestions would predict a limited number of definite interfaces. The present study indicates that in solution treated and quenched alloys Type I on further treatment can grow into Type II, which is non-coherent to the Al matrix without the coincident site lattices (CSL) between the S phase and Al matrix. Thus, in thermodynamic sense, Type II is the more stable variant. 


\subsection{Chemistry of Type II S phase}

It is commonly accepted that there are three ways to form $\mathrm{S}$ phase: by heterogeneous nucleation from vacancy loops, by heterogeneous nucleation on dislocations, and by transformation of or nucleation on the intermediate precipitate S". Si inhibits the formation of vacancy loops during/after quenching, and therefore suppresses the availability of heterogeneous nucleation sites [29].

In their study of a quenched and aged Al-2.96Mg-0.42Cu-0.12Si-0.25Mn-0.21Fe alloy using EDS and 3DAP, Kovarik et al. [24] showed that about $1 \mathrm{wt} . \%(\approx$ at- $\%)$ of Si concentrate at or close to the interface of Type II S phase (but they termed the precipitate S" phase) and Al matrix. Accordingly, Kovarik et al. [24] proposed that Si might promote the formation of Type II S phase precipitates in their alloy. However, the EDS analysis in the present AA2x24 alloys did not show any Si enrichment in or around the Type II precipitates, for example in the AA2324 alloy as shown in Fig. 3(d). In comparison with the DSC peaks $\left(\mathrm{C}_{\mathrm{II}}\right)$ for the formation of Type II precipitates in the AA2024 alloy with $0.49 \mathrm{wt} \% \mathrm{Si}$ and in the AA2324 alloy with $0.08 \mathrm{wt} \% \mathrm{Si}$ (Fig. 5), the $\mathrm{C}_{\text {II }}$ peak of AA2024 is lower than the corresponding $\mathrm{C}_{\text {II }}$ peak of AA2324 alloy. This means that the high level of Si does not promote the formation of Type II phase precipitates in AA2x24 alloys. Instead it promotes formation of Type I S phase.

\subsection{Nomenclature for Type I and Type II S phase}

As part of the present discussion, we will attempt to provide a nomenclature for the observed phases that takes the present findings into account and is as much as possible consistent with the past literature. In many publications $[1-3,8,10,21], \mathrm{S}^{\prime}$ and $\mathrm{S}$ in (SQ1) have been considered to have the same structure and the same orientation relationships with aluminium matrix (i.e. no rotation). The only distinction is the small difference in lattice parameters, with S' being semi-coherent and S non-coherent with aluminium matrix. This distinction, however, is not supported by the majority of experiments, and many recent publications make no distinction between the $\mathrm{S}^{\prime}$ and S phase [14-19,22], instead considering the two types are indistinguishable in terms of lattice structure and lattice parameters. To take account of this and other recent developments in understanding of the precipitation sequence in these alloys, SQ3 has been proposed [4,19]. Combining the present findings with SQ3, the sequence for the formation of $\mathrm{S}$ phase by homogenous nucleation is suggested to be best represented as:

$$
\mathrm{SSS} \rightarrow \text { Clusters } \rightarrow \mathrm{S} / \text { GPB2 } \rightarrow \text { S (Type I) } \rightarrow \text { S (Type II) }
$$

Alternatively, one could term the less stable S phase variant (the Type I variant) as S' and Type II as S. This is similar to the traditional terminology for precipitates in quenched, cold worked and subsequently artificially aged $\mathrm{Al}-\mathrm{Cu}-\mathrm{Mg}$ alloys, which indicates the dense precipitates, which were in this work shown to be Type I, as S'. Whilst this may be preferred by a range of researchers, we would note that this can introduce confusion because Type II S precipitates as analysed in the present work are different from the common definition for S (as used in SQ1) in that it is actually rotated by a few degree to the S phase in SQ1. To expand on this issue, the comparison between $\mathrm{S}$ (Type I) and S (Type II) in this work shows that both types have the same lattice parameters but slightly different OR, whereas $S^{\prime}$ and $S$ in SQ1 are supposed to have slightly different lattice parameters but the same OR. If researchers prefer to continue to use the indication $\mathrm{S}^{\prime}$, we would suggest that the term should be followed by a brief clarification. Another alternative, terming Type I as S", would cause confusion in comparison with earlier works in which the term $S^{\prime \prime}$ is used for phases with crystal structures different from $S$ phase. A third alternative, which seems to be close to the phase terminology adopted by Kovarik et al. [24], would be to term Type II as S". The present results show that in AA2x24 series alloys Type II is more stable than Type I and hence also the third choice of phase terminology would cause confusion. We believe the terms S (Type I) and S (Type II) are the best choice.

\subsection{Effect of deformation on the formation of Type II phase}

As shown in Fig.1, the DSC peak for the formation of Type II S phase did not appear in the T351 sample (which had been 1.5-3\% stretched) and in cold worked (10\% cold work) samples. The S precipitates in the cold worked and subsequently artificially aged sample (Fig. 6) have a much smaller size and more homogenous distribution than the ones in samples without cold work (Fig. 2). TEM observations in Fig. 7 also show that the transformation from Type I to Type II S precipitates is much more sluggish as compared to solution treated samples without deformation. Nevertheless, Type I S phase precipitates should eventually transform to Type II, which is the more stable version in a thermodynamic sense. The reason why the deformation delays the transformation from 
Type I to Type II can be understood by the following arguments. Type I phase is semi-coherent with Al matrix, thus Type I would be expected to be a slightly distorted version of the equilibrium $\mathrm{S}$ phase structure, with dislocations accommodating the strains at the interfaces with the matrix. As the temperature increases, dislocations would gradually anneal out and Type I will become more unstable with respect to Type II. In undeformed samples, which at the start of ageing have a very low concentration of dislocations, this can lead to formation of Type I being incomplete, with the remainder of $\mathrm{Cu}$ and $\mathrm{Mg}$ in solution directly forming Type II S phase. This explains the appearance of two peaks in the DSC thermograms of as solution treated samples. (It should be noted here that the transformation from Type I to Type II is expected to have merely a small heat effect, as both are essentially the same phase, and only strain energy and interfacial energy is released. Thus the appearance of two distinct effects of same order of magnitude in Fig. 1 suggests that transformation of Type I to Type II cannot be the only cause of the second effect. Rather, some of the Type II S phase is expected to form from the remainder of the dissolved elements.) In cold worked samples, the availability of an abundance of dislocations will first promote full formation of Type I S phase, and cause the dislocation density to remain relatively high (higher than samples that are not cold worked) during further heat treatment, promoting the stability of Type I S phase.

Because each type of $\mathrm{S}$ phase precipitates has 12 equivalent ORs, Radmilovic et al [22] suggested that there would be 24 instead of 12 precipitate orientations if these two types of S precipitates coexist. This would provide a more homogenous dispersion, which was expected to benefit the mechanical properties of these alloys [22]. This was based on the assumption that Types I and II precipitates nucleate independently and coexist. However, the combination of DSC and TEM in this study indicates that two types of precipitates form in a sequence and tend to not nucleate separately in close proximity such that any beneficial effect in hampering dislocation movement could occur. Further more, Type II precipitates have a more limited effect in strengthening the alloy as they are relatively large in size (see Figs. 2-4). Therefore, increasing the heterogeneous nucleation such as by cold work, will delay the formation of Type II precipitates and improve the strength at peak ageing as well as during overageing.

\section{Conclusions}

TEM and DSC have been used to study the formation of two variants of $\mathrm{S}$ phase precipitation in an $\mathrm{Al}-4.2 \mathrm{Cu}-$ $1.5 \mathrm{Mg}-0.6 \mathrm{Mn}-0.5 \mathrm{Si}$ (AA2024) and an Al-4.2Cu-1.5Mg-0.6Mn-0.08Si (AA2324) (wt.\%) alloy. In DSC experiments on as solution treated samples two distinct exothermic peaks are observed in the range 250 to $350^{\circ} \mathrm{C}$, whereas only one peak is observed in solution treated and subsequently stretched or cold worked samples. The combination of DSC and TEM experiments in Al-Cu-Mg alloys confirm the existence of two distinct S phase precipitates, which correspond to two exothermic DSC effects in solution treated samples between $230^{\circ} \mathrm{C}$ and $350^{\circ} \mathrm{C}$. Type I precipitates have the classic OR $\left([100]_{\mathrm{S}\left(\mathrm{S}^{\prime}\right)} / /[100]_{\mathrm{Al}},[010]_{\mathrm{S}\left(\mathrm{S}^{\prime}\right)} / /[02 \overline{1}]_{\mathrm{Al}},[001]_{\mathrm{S}\left(\mathrm{S}^{\prime}\right)} / /[012]_{\mathrm{Al}}\right)$, and Type II precipitates have an OR rotated by $\sim 4^{\circ}$. Type II is a non-coherent precipitate and is the more stable of the two. In solution treated quenched and subsequently cold worked samples, extensive formation of Type I occurs, whilst formation of Type II is suppressed. Increased Si content enhances the formation of Type I S phase during DSC experiments, and decreases the formation of Type II S phase. The sequence for the formation of S phase by homogenous nucleation is suggested as

$$
\mathrm{SSS} \rightarrow \text { Clusters } \rightarrow \mathrm{S} " / \mathrm{GPB} 2 \rightarrow \mathrm{S} \text { (Type I) } \rightarrow \mathrm{S} \text { (Type II) }
$$

The formation of Type II phase precipitates is strongly dependent on solution treatment and cold work. Type II phase has random interfaces with the matrix, which indicates the transformation from Type I to Type II is not the result of an invariant line transformation strain.

\section{References}

[1] Bagaryatsky, YA. Dokl Akad SSSR 1952;87:397 \& 559.

[2] Silcock JM. J Inst Met 1960-61;89:203.

[3] Cuisiat F, Duval P, Graf R. Script Met 1984;18:1051.

[4] Wang SC, Starink MJ. Mater Sci Eng A 2004;386:156.

[5] Kovarik L, Gouma PI, Kisielowski C, Court SA, Mills MJ. Acta Mater 2004;52:2509.

[6] Shih H, Ho N, Huang JC. Metall Mater Trans A 1996; 27:2479.

[7] Wolverton C. Acta Mater 2001;49:3129.

[8] Charai A, Walther T, Alfonso C, Zahra AM, Zahra CY. Acta Mater 2000;48:2751.

[9] Perlitz H, Westgren A. Arkiv Kemi Mineral Geol 16B;1943:No13. 
[10] Mondolfo LF. Aluminum alloys-Structure and Properties, Butterworths, London, 1976.

[11] Gupta AK, Gaunt P, Chaturvedi MC. Phil Mag A 1987;55:375.

[12] Alekseev AA, Anan'ev VN, Ber LB, Kaputkin EY. The Physics of Metals and Metallography 1993;75:279.

[13] Li C, Yan M. Mater Sci \& Eng 1983;57:143.

[14] Ringer SP, Hono K, Polmear IJ, Sakurai T. Acta Mater 1996;44:1883.

[15] Ringer SP, Caraher SK, Polmear IJ. Script Mater 1998;39:1559.

[16] Starink MJ, Gao N, Yan JL. Mater Sci Eng A 2004;387-389:222.

[17] Starink MJ, Cerezo A, Yan JL, Gao N. Phil Mag Lett 2006;86:243.

[18] Wang SC, Starink MJ, Gao N. Script Mater 2006;54:287.

[19] Wang SC, Starink MJ. Int Mater Rev 2005;50:193.

[20] Starink MJ, Gao N, Davin L, Yan JL, Cerezo A. Phil Mag 2005;85:1395.

[21] Zhang CB, Sun W, Ye HQ. Phil Mag Lett 1989;59:265.

[22] Radmilovic V, Kilaas R, Dahmen U, Shiflet GJ. Acta Mater 1999;47:3987.

[23] Majimel J, Molenat G, Danoix, F, Blavette D, Lapasset G, Casanove MJ. Mater Sci Forum 2002;239402:1025.

[24] Kovarik L, Miller MK, Court SA, Mills MJ. Acta Mater 2006;54:1731.

[25] Starink MJ. Int Mater Rev 2004;49:191.

[26] Lefebvre F, Wang SC, Starink MJ. Sinclair I. Mater Sci Forum 2002;396-402:1555.

[27] Wang SC, Lefebvre F, Yan JL, Sinclair I, Starink MJ. Mater Sci Eng A 2006;431:123

[28] Khan IN, Starink MJ. Mater Sci Forum 2006;519-521:277.

[29] Sen N, West DRF. J Inst Met 1969;97:87.

[30] Starink MJ. Thermochim Acta 2003;404:163.

[31] Yan JL. PhD thesis, The University of Southampton, 2006. 